\title{
Effect of Heat Stress on Farm Workers - A Review
}

\author{
Surabhi Singh ${ }^{1 *}$, Santosh Ahlawat ${ }^{2}$ and Sarita Sanwal ${ }^{3}$ \\ ${ }^{1}$ FRM, Sardarkrushinagar Dantiwada Agricultural University, Gujarat, India \\ ${ }^{2}$ HECM, Sardarkrushinagar Dantiwada Agricultural University, Gujarat, India \\ ${ }^{3}$ HDFS, Sardarkrushinagar Dantiwada Agricultural University, Gujarat, India
}

*Corresponding author

\section{A B S T R A C T}

\begin{tabular}{|l|}
\hline Ke y w o r d s \\
Heat Stress, Farm \\
Workers, Temperatures \\
\hline Article Info \\
\hline Accepted: \\
18 September 2018 \\
Available Online: \\
10 October 2018 \\
\hline
\end{tabular}

Farm workers do arduous work continuously under extreme weather condition. Knowledge about farmers experiences regarding heat and climate change is prerequisite and fundamental for policy making strategies implementation to protect them from climate change. Hence, this article reviews this indispensable area of effect of heat stress on farmers. This will present exhaustive reviews and conclusion of the researches with objectives to review the results of various researches on heat stress of farmers and to recommend various practices to be followed for preventing heat stress. WBGT index was used to evaluate heat conditions while various physiological parameters of workers such as CBT, heart rate, blood pressure etc. were also measured to know effect of excessive heat on their health. It was found that high WBGT Index ensued to higher CBT and heart rate while lower blood pressure. Researchers also cited that heat stress affects adversely kidney and hormonal balance of body.

\section{Introduction}

The impact of climate change expressed as increased temperatures, changes in precipitation, more extensive flooding, and enhanced drought and heat waves, is projected to be different in each geographic location (Schellnhuber, 2008). A substantial part of researches focused on climate change, reasons, gas emissions from greenhouses but a few of them were carried on effect of increasing temperature on health of working population, especially who work outdoors. Farm workers do arduous work continuously under extreme weather condition. Knowledge about farmers experiences regarding heat and climate change is prerequisite and fundamental for policy making strategies implementation to protect them from climate change. Hence, this article reviews this indispensable area of effect of heat stress on farmers. This will present exhaustive reviews and conclusion of the researches with following objectives-

To review the results of various researches on heat stress of farmers

To recommend various practices to be followed for preventing heat stress 
Heat stress can be defined as the sum of environmental and metabolic heat loads which increases the core body temperature (CBT) of an individual and may affect adversely many physiological parameters. It has been proved in researches that severe heat and harsh environmental conditions impend for occurrence of heat illness (Jackson and Rosenberg, 2010).

There is a dearth of researches on measuring effect of heat on farm workers. Farm worker is a vulnerable population of India which suffers from heat illness. Farm workers work hard outdoors even in adverse environmental conditions.

\section{Methods for evaluating heat stress and its effect on farm workers}

WBGT (Wet bulb globe thermometer) Index was found the most common method for reporting environment heat condition. There were many other environmental parameters recorded in researches such as air temperature, natural wet temperature, globe temperature, relative humidity and air velocity. Furthermore, WBGT and Humidex were found more accurate methods to show better association with physiological parameters under heat stress condition.

WBGT (Wet bulb globe thermometer) Index was used to monitor environmental changes in a study conducted in Iran (Heidari et al., 2015); while mean skin temperature, aural temperature and oral temperature were used to study effect of WBGT index on physiological parameters.

It has been concluded that high WBGT index results high mean skin temperature and the correlation coefficient between the aural temperature and WBGT was found highly significant $(r=0.84, P<0.001)$. Hence, to evaluate the effect of heat stress, mean skin temperature and aural temperature were found better parameters to be measured in combination of WBGT.

Kashyap et al., (2017) measured oral temperature, mean skin temperature and heart rate to evaluate the effect of environmental heat on farm workers. With the increment of WBGT from 28 to $30^{\circ} \mathrm{C}$, all these physiological parameters had raised. Besides, overall discomfort rate also increased from 4.9to 6.7 during same working condition.

Local heat exposure levels in Southern India were measured via WBGT in various organized and unorganized workplaces during both hotter and cooler months. Agriculture sector was also selected in this study and it was found that all respondents perceived negative impact of heat on their health and 70 per cent perceived negative impact on their productivity (Venugopal et al., 2016).

Jackson and Rosenberg (2010) stated that excessive heat may cause heat rash, heat syncope, heat cramps, heat exhaustion, and heatstroke. Heat rash is an irritating skin inflammation from clogged sweat glands. Heat syncope is a temporary loss of consciousness due to insufficient blood and oxygen to the brain. Heat cramps are painful muscle contractions generally induced by an electrolyte imbalance after intense sweating.

Heat exhaustion may present as muscle weakness, fatigue, and a host of other symptoms during strenuous work in a hot environment after dehydration reduces blood volume and circulation. Heat stroke is the frequently fatal result of complete breakdown of the body's thermoregulation ability. As well as, temperature increases the level of heat illness also gets worse. The temperature more than or equal to $100^{\circ} \mathrm{F}$ may end up with fatal or non-fatal heat stroke. Even non-fatal heat stroke may result into organ failure. 
Further, it has been proven that heart rate, rectal muscle temperature increased as a result of heat stress. Besides, ammonia accumulation was also found increased in excessive heat (Snow et al., 1993).On a contrary, Parsons (2003) reported in a study that vasodilation (widening of blood vessels) enhanced ease of body movement when the body is hot. Although workers felt discomfort, fatigue and psychological strain under heat stress.

It has been reported by Zahra et al., (2017) that all heat indices had direct association with physiological parameters of farmers such as pulse rate and core body temperature. Though, blood pressure of farmers had reduced with an increase in heat indices. It was found in this study that heat stress indices WBGT and Humidex were more powerful to show better association with mentioned physiological parameters.

Mirabelli et al., (2010) reported that working in extreme heat was reported by 281 respondents (94\%), among whom 112 (40\%) reported symptoms of heat illness. Changes in work hours and activities during hot conditions were associated with a lower prevalence of heat illness among $\mathrm{H}-2 \mathrm{~A}$ workers but not among non-H-2A workers.

Tjaša et al., (2017) concluded in their study that the most common symptoms of heat stress amongst farmers were reported as excessive sweating, thirst and tiredness. Interestingly, farmers under 40 years reported more problems on these issues compared to farmers above 40 years and more females experienced tiredness and dizziness as compared to male.

Jain et al., (2015) analyzed biochemical effect of heat stress and found that humans when exposed to heat stress showed dehydration and increase in core body temperature. The acute heat stress also affected the hormonal balance of the body.

The most frequently mentioned problems by nursery and fernery workers were: headaches, dizziness/fainting, respiratory problems, vomiting, and exacerbated high or low blood pressure. Less frequently mentioned were sunstroke and heart attack (Flocks et al., 2013).

\section{Interventions and strategies for preventing heat stress}

Heidari (2015) felt a need of increasing farmers' awareness on heat stress, providing them health care and taking heat preventive measures at workplace to reduce health hazards due to extreme heat condition. Researchers reported an urge to recommend official guidelines for farmers in relation to implementing solutions to mitigate heat stress. Jackson and Rosenberg (2012) suggested that along with taking other preventive measures; frequency and duration of rest periods must be adjusted according to the intensity of heat indices. More water consumption should also be encouraged by the agricultural workers in hot environment. Lam et al., (2013) recommended strategies for heat related illness prevention which included health promotion, use of personal protective equipment, administrative and engineering strategies.

Tjasa et al., (2017) found in their research that more water intake, rest periods at cooler places and wearing light clothing were counter measures to prevent heat related illness. Preventive clothing was found essential for many occupations including agriculture for reducing health hazards (Gao et al., 2017).

Kwasil et al., 2014 stated Government should take long term measure, such as providing or 
encouraging well-ventilated accommodation in farming communities and developing programs of mechanized farming to reduce human physical outlay of labor in hot temperatures.

WBGT index was used to evaluate heat conditions while various physiological parameters of workers such as CBT, heart rate, blood pressure etc. were also measured to know effect of excessive heat on their health. It was found that high WBGT Index ensued to higher CBT and heart rate while lower blood pressure. Researchers also cited that heat stress affects adversely kidney and hormonal balance of body. Hence, it can be construed that farm workers toil in adverse environmental conditions. Excessive heat is one of the most common problems faced by farm workers. It is high time to intervene and make some strategies to prevent farm workers from heat illness. Few of them may be as given below-

Providing sufficient rest hours and adjust working hours so that they don't work in excessive heat hours.

Rules and regulations should be framed and implemented for protection of farm workers from heat. They should wear protective clothing mandatory and drinking water should be available at work place.

Awareness about heat related illness and its effect should be extended amongst farm workers. They should imparted trainings on heat preventive measures.

Their health checkup should be regular during hot summer days to prevent them from any worse situation.

Any sign of heat illness should be treated properly. Facilities of emergency medical services should be provided.

\section{References}

Heidari H., Golbabaei F., Shamsipour A., Forushani A. R., Gaeini A. 2015. Evaluation of Heat Stress among Farmers Using Environmental and Biological Monitoring: A study in North of Iran. International Journal of Occupational Hygiene, 7: 1-9.

Jackson L. L., Howard TED, Rosenberg R., 2010. Preventing Heat-Related Illness among Agricultural Workers. 2010 Journal of Agromedicine, 15:200-215.

Kashyap V., Mehta A.K., Amitabh A. and Mahapatra J. 2017. Effect of Environmental Heat on the Performance of Female Farm Workers for Agriculture Operation. Int.J.Curr. Microbiol.App.Sci. 6(12): 3295-3302. doi: https://doi.org/10.20546/ijcmas. 2017.612.383.

Lam et al., BMC Public Health 2013. 13:1004 http://www.biomedcentral.com/14712458/13/1004.

Mirabelli M C et al., 2010. Symptoms of Heat Illness among Latino Farm Workers in North Carolina, American Journal of Preventive Medicine, 39 (5): 468-471.

Parsons K. 2003. Human thermal environments, 2nd Ed., Taylor and Francis, New York.

Snow J. R., Febbraio M. A., Carey M. F., Hargreaves M. 1993. Heat Stress Increases Ammonia Accumulation during Exercise in Humans. Experimental Physiology, 78, 847-850.

Tjaša, Zalika, Lučka and Lars, 2017. Comprehension of climatic and occupational heat stress amongst agricultural advisers and workers in Slovenia. Acta Agriculturae Slovenica, 109 - 3, 545-554.

Venugopal V., Chinnadurai J. S., Rebekah A. I. L. and Kjellstrom T., 2016. Occupational Heat Stress Profiles in 
Selected Workplaces in India, Int. J. Environ. Res. Public Health.13, 89.

Xiang, Peng B., Pisaniello D., Hansen A. 2014. Health Impacts of Workplace Heat Exposure: An Epidemiological Review. Industrial Health 2014, 52, $91-$ 101.
Zahra Z., Zahra S., Masoud H. and Farahnaz K., 2017. Evaluation of environmental heat stress on physiological parameters. Zamanian et al., Journal of Environmental Health Science \& Engineering. 15:24.

\section{How to cite this article:}

Surabhi Singh, Santosh Ahlawat and Sarita Sanwal. 2018. Effect of Heat Stress on Farm Workers - A Review. Int.J.Curr.Microbiol.App.Sci. 7(10): 2397-2401. doi: https://doi.org/10.20546/ijcmas.2018.710.278 